\title{
Novel perspectives for evolving enzyme cocktails for lignocellulose hydrolysis in biorefineries
}

\author{
Saritha Mohanram, Dolamani Amat, Jairam Choudhary, Anju Arora* and Lata Nain
}

\begin{abstract}
The unstable and uncertain availability of petroleum sources as well as rising cost of fuels have shifted global efforts to utilize renewable resources for the production of greener energy and a replacement which can also meet the high energy demand of the world. Bioenergy routes suggest that atmospheric carbon can be cycled through biofuels in carefully designed systems for sustainability. Significant potential exists for bioconversion of biomass, the most abundant and also the most renewable biomaterial on our planet. However, the requirements of enzyme complexes which act synergistically to unlock and saccharify polysaccharides from the lignocellulose complex to fermentable sugars incur major costs in the overall process and present a great challenge. Currently available cellulase preparations are subject to tight induction and regulation systems and also suffer inhibition from various end products. Therefore, more potent and efficient enzyme preparations need to be developed for the enzymatic saccharification process to be more economical. Approaches like enzyme engineering, reconstitution of enzyme mixtures and bioprospecting for superior enzymes are gaining importance. The current scenario, however, also warrants the need for research and development of integrated biomass production and conversion systems.
\end{abstract}

Keywords: Lignocellulose, Bioethanol, Cellulase, Hemicellulase, Bioprospecting, Enzymatic saccharification

\section{Introduction}

Increased public and scientific attention towards alternative energy sources is driven by forces like spiralling oil prices, the need for obtaining sustainability in energy supplies and increased energy security and above all concern over climate change due to high emissions from fossil fuels. It is extremely important that the new sustainable energy sources developed reduce our reliance on fossil fuels for our major energy needs. The transportation sector depends almost entirely on liquid fuels and consumes a major portion of the petroleum based fuels. Policy interventions, in the form of subsidies and mandated blending of biofuels with fossil fuels are driving the rush to liquid biofuels [1], which include biodiesel, bioethanol and biobutanol. Bioenergy, in the form of biofuels, can contribute to economic development and to the environment through climate change mitigation as biofuels offer $\mathrm{C}$ neutral alternative. According to the US Environmental Protection Agency, use of ethanol blended gasoline can cut down $\mathrm{CO}_{2}$ emissions by $25-30 \%$.

\footnotetext{
* Correspondence: anjudev@yahoo.com

Division of Microbiology, Indian Agricultural Research Institute, New Delhi 110012 , India
}

Investment into biofuels production capacity exceeded $\$ 4$ billion worldwide in 2007 and is growing. Biofuels provided $1.8 \%$ of the world's transport fuel in 2008 [2]. India has a pressing need for renewable transportation fuels and mandates use of $5 \%$ bioethanol blending in motor gasoline in several states [3]. The blending targets for ethanol and biodiesel in gasoline and petroleum diesel, respectively, were proposed at $10 \%$ and $20 \%$ by 2011-2012 [4]. Hence, biofuels have to be produced in much higher volume in order to meet this demand.

Biofuels are solid, liquid or gaseous fuels obtained relatively from recently dead biological material and are distinguished from fossil fuels, which are derived from long dead biological material. Biofuels employ recycling of agricultural byproducts and dedicated energy crops, which offer opportunities for mitigation of greenhouse gas emission as growing these leads to $C$ sequestration through photosynthesis. Various plants and plant-derived materials are used for biofuels manufacturing including grains (1st generation) and lignocellulosic biomass (2nd generation). The 'second generation' of biofuels is more important as they are based on the cheap and abundant lignocellulosic 
biomass and do not compete with food crops. When greenhouse gas emission from production and use of biofuels is taken into account, the first generation biofuels frequently approach those of traditional fossil fuels. On the other hand, second generation biofuels can help solve the problem of GHG emission and can contribute to a larger proportion of our fuel supply sustainably, affordably and with greater environmental benefits. The era of advanced biofuels - cellulosic ethanol, biomass-based diesel, biobutanol, bio-oil, green gasoline and bio-based jet fuel - is also drawing nearer and nearer. According to the International Energy Agency, biofuels have the potential to meet more than a quarter of world demand for transportation fuels by 2050 . Bioethanol is by far the most widely used biofuel for transportation worldwide.

However, technological and economical hurdles impede the development and commercialization of biofuels. Analyses indicate that with the exception of bioethanol from sugarcane in Brazil, biofuels are generally not economically competitive with fossil fuels without subsidies [1]. The cost and success of the biomass to bioethanol process depend largely on the inherent recalcitrance of biomass and the repertoire of enzymes involved in depolymerization of the constituent polysaccharides. With massive investments and government initiative in green infrastructure and renewable energy expected to take place, interest in biomass conversion technologies is on the rise.

For production of second generation cellulosic ethanol, polysaccharides present in lignocellulosic materials (such as agro and forestry residues, herbaceous grasses and woody plants), including cellulose and hemicellulose are of great interest as feedstocks. The technological outline developed for the production of fuel from lignocellulose involves the following steps. First, the cellulose and hemicellulose portions of the biomass must be broken down into sugars and a variety of pretreatments are required to carry out this saccharification step in an efficient and low-cost manner. Second, these sugars which are a complex mixture of 5-carbon and 6-carbon sugars must be fermented to make bioethanol. Low efficiency due to the natural recalcitrance of lignocellulose to deconstruction and high cost of enzymatic conversion, therefore, form the major bottlenecks in this technology. Significant research, therefore, have to be directed towards the identification of efficient cellulase systems and process conditions, besides those aimed at the biochemical and genetic improvement of existing organisms utilized in the process.

\section{Biomass to ethanol bioconversion process}

With an impressive annual production estimated at $1 \times 10^{10}$ MT worldwide, lignocellulosic biomass is, considered as the only foreseeable, feasible and sustainable resource for renewable energy and value added chemicals [5].
Lignocellulosic complex is the most abundant biopolymer on the earth and comprises about 50\% of world biomass [6]. Lignocellulose feedstocks, such as agricultural and forest residues, industrial and municipal wastes, and dedicated energy crops, by virtue of their high carbohydrate content, hold tremendous potential for large-scale bio ethanol production [7]. Lignocellulosic biomass mainly contains cellulose, a homopolymer of glucose, in bound form along with hemicelluloses and lignin and typically, lignocellulosic biomass contains about 40-60\% cellulose, 20-40\% hemicelluloses, and 10-25\% lignin [8]. The cell wall polysaccharides can be hydrolysed into monomeric sugars which are used for biorefining to produce a range of bio-materials. Fermentation, chemical catalysis, or other processes may then be used to create novel products such as ethanol or other valuable chemical intermediates that can be used as chemical feedstocks in manufacturing processes.

Ethanol from biomass is obtained by fermentation of carbohydrates present in biomass. In case of first generation biofuels this carbohydrate is usually sucrose or starch which is relatively easier to convert into simpler fermentable sugars. However, in case of second generation ethanol, the complex lignin-cellulose-hemicelluloses matrix of the biomass has to be disintegrated and the carbohydrate polymers need to undergo hydrolysis to yield fermentable sugars. This hydrolysis step is typically catalyzed by cocktails of enzymes including cellulases, hemicellulases and other accessory enzymes that target and degrade specific constituents of cell wall. Enzymatic hydrolysis has renewed and increased the focus on several aspects of cellulases as they play a key role in determining the economics of operation. The impediments, which include development of robust biocatalysts and cost of cellulases, have to be overcome for successful commercialization of biofuels. A cost effective enzyme technology to degrade polysaccharides into fermentable sugars is imperative for economically viable biofuels. This include search for hyper-cellulase producing organisms, developing superior cellulases with improved characteristics such as higher efficiencies, increased stability at elevated temperatures, and higher tolerance to end product inhibition and also inhibition by pretreatment byproducts, using advanced biotechnologies [9].

\section{Enzymatic saccharification of cellulose and hemicellulose}

Majority of plant biomass is locked up in 5- and 6carbon sugars, comprised of mainly cellulose (a glucose homopolymer); less so, hemicelluloses (a sugar heteropolymer); and least of all lignin (a complex aromatic polymer). The major component cellulose, which is organized into microfibrils, each containing up to 36 glucan chains having thousands of glucose residues linked by $\beta$ - $(1,4)$ glycosidic bonds, is largely responsible for the 
plant cell wall's mechanical strength [10]. Hemicelluloses are built up by pentoses (D-xylose, $\mathrm{D}$-arabinose), hexoses (D-mannose, D-glucose, D-galactose) and sugar acids. These include $\beta$-glucan, xylan, xyloglucan, arabinoxylan, mannan, galactomannan, arabinan etc. Hardwood contains mainly xylans, while in softwood glucomannans are most common. Both the cellulose and hemicellulose can be broken down enzymatically into the component sugars which may be then fermented to ethanol $[8,11]$.

The first attempt at commercialization of a process for ethanol from wood was done in Germany in 1898. It involved use of dilute acid to hydrolyse cellulose to glucose and produced $7.6 \mathrm{~L}$ ethanol per $100 \mathrm{Kg}$ of wood waste [12]. This process soon found its way to other countries and the acid hydrolysis gradually got replaced by enzymatic hydrolysis as the acids and high temperature employed to degrade polysaccharides generated undesirable byproducts. The application of enzymes for hydrolysis of wood in an ethanol process is called separate hydrolysis and fermentation [13]. A more cost-effective process alternative is simultaneous saccharification and fermentation (SSF) in which the two steps of enzymatic hydrolysis and fermentation are carried out together in a vessel. As suggested by Das et al., [14] SSF processes utilizing recombinant enzymes have the potential to minimize the production costs and maximizing the volumetric productivity in the bio-ethanol industry. Utility cost of enzymatic hydrolysis is low compared to acid or alkaline hydrolysis because enzyme hydrolysis is usually conducted at mild conditions ( $\mathrm{pH} 4.8$ and temperature $45-50^{\circ} \mathrm{C}$ ) and does not have a corrosion problem [15].

The classical model for degradation of cellulose to glucose involves the cooperative action of endocellulases (EC 3.2.1.4), exocellulases (cellobiohydrolases, $\mathrm{CBH}$, EC 3.2.1.91; glucanohydrolases, EC 3.2.1.74), and betaglucosidases (EC 3.2.1.21). Endocellulases hydrolyze internal glycosidic linkages in a random fashion, which results in a rapid decrease in polymer length and a gradual increase in the reducing sugar concentration. Exocellulases hydrolyze cellulose chains by removing mainly cellobiose either from the reducing or the nonreducing ends, which lead to a rapid release of reducing sugars but little change in polymer length. Endocellulases and exocellulases act synergistically on cellulose to produce cello oligosaccharides and cellobiose, which are then cleaved by beta-glucosidase to glucose [16]. Hydrolysis of hemicelluloses involve enzymes like glycoside hydrolases, carbohydrate esterases, polysaccharide lyases, endohemicellulases and others, the concerted action of which hydrolyze glycosidic bonds, ester bonds and remove the chain's substituents or side chains [17]. These include endo- 1 , 4 - $\beta$-xylanase, $\beta$,-xylosidase, $\beta$-mannanase, $\beta$ mannosidase $\alpha$-glucuronidase, $\alpha$ - L-arabino furanosidase, acetylxylan esterase and other enzymes.

\section{Microbial sources of cell wall degrading enzymes}

Trichoderma reesei was one of the first cellulolytic organisms isolated in 1950s. By 1976, an impressive collection of more than 14,000 fungi which were active against cellulose and other insoluble fibres were collected [18]. However, industrial cellulases are almost all produced from aerobic cellulolytic fungi, such as Hypocrea jecorina (T. reesei) or Humicola insolens [19]. This is due to the ability of engineered strains of these organisms to produce extremely large amounts of crude cellulase (over $100 \mathrm{~g}$ per liter) with a relatively high specific activity on crystalline cellulose and the ability to genetically modify these strains to tailor the set of enzymes they produce, so as to give optimal activity for specific uses [20]. Both fungi and bacteria have been heavily exploited for their abilities to produce a wide variety of cellulases and hemicellulases for the hydrolysis of lignocellulosic materials [21]. Most emphasis has been placed on the use of fungi because of their capability to produce copious amounts of cellulases and hemicellulases which are secreted to the medium for easy extraction and purification. Apart from the cellulolytic fungus $T$. reesei, many other fungi produce cellulases and degrade treated cellulosic material or soluble cellulose derivatives such as carboxymethylcellulose. However, they are not very effective on crystalline cellulosic substrates. Mesophilic strains producing cellulases like Fusarium oxysporium, Piptoporus betulinus, Penicillium echinulatum, P. purpurogenum, Aspergillus niger and A. fumigatus have also been reported [22-24]. The cellulases from Aspergillus usually have high $\beta$-glucosidase activity but lower endoglucanase levels, whereas, Trichoderma has high endo and exoglucanase components with lower $\beta$-glucosidase levels, and hence has limited efficiency in cellulose hydrolysis. Thermophillic microorganisms such as Sporotrichum thermophile, Scytalidium thermophillum, Clostridium straminisolvens and Thermomonospora curvata also produce the cellulase complex and can degrade native cellulose $[25,26]$. Such thermophilic organisms may be valuable sources of thermostable cellulases.

To date, the majority of enzymes developed and being tested for lignocellulose degradation are from fungi. A reasonable question is how much additional progress is possible with fungal-based enzymes or whether the way forward will require new prokaryotic paradigms [27]. The isolation and characterization of novel glycoside hydrolases from Eubacteria are now becoming widely exploited. There are several reasons for these shifts, for one, bacteria often have a higher growth rate than fungi allowing for higher recombinant production of enzymes. Secondly, bacterial glycoside hydrolases are often more complex and are often expressed in multi-enzyme complexes providing increased function and synergy. Most importantly, bacteria inhabit a wide variety of environmental and industrial niches, which produce cellulolytic 
strains that are extremely resistant to environmental stresses. These include strains that are thermophilic or psychrophilic, alkaliphilic or acidiophilic, and, strains that are halophilic. Not only can these strains survive the harsh conditions found in the bioconversion process, but also they can produce enzymes that are stable under extreme conditions which may be present in the bioconversion process and this may increase rates of enzymatic hydrolysis, fermentation, and, product recovery [28].

Bacteria belonging to Clostridium, Ruminococcus, Bacteriodes, Erwinia, Acetovibrio, Microbispora and Streptomyces can produce cellulases [29]. Cellulomonas fimi and Thermomonospora fusca have been extensively studied for cellulase production. Similarly, other bacterial strains have the ability to produce cellulase complexes aerobically as well as anaerobically. Cellulase producing bacterial strains of Rhodospirillum rubrum, Cellulomonas fimi, Clostridium stercorarium, Bacillus polymyxa, Pyrococcus furiosus, Acidothermus cellulolyticus, and Saccharophagus degradans have been extensively reviewed [16,25,30,31]. An extracellular alkaline carboxy methyl cellulase (CMCase) from Bacillus subtilis strain AS3 has been purified and characterized by Deka et al. [32] for utilization of cellulosic biomass. Although many cellulolytic bacteria, particularly the cellulolytic anaerobes such as Clostridium thermocellum and Bacteroides cellulosolvens produce cellulases with high specific activity, they do not produce high enzyme titres [33].

Bacterial enzymes involved in degradation of hemicellulases have also been the focus of several studies. Many bacterial strains like Bacillus circulans, Bacillus amyloliquefaciens, Clostridium thermocellum, Thermobacillus xylanolyticus, Bacillus subtilis, Dictyoglomus thermophillus, and Streptomyces halstedi are found to be sources of hemicellulases [28]. A glycoside hydrolase family 43 (GH43) from Clostridium thermocellum showing hemicellulase activity, along with its further use in simultaneous saccharification and fermentation process has been described [32]. Commercial development of hemicellulases for enzymatic hydrolysis of lignocellulosics is not as advanced as cellulases because current commercial preparations have been primarily on dilute acid pretreated biomass where hemicellulose is removed before saccharification [34]. However, if the pretreatment is non-acidic, where the hemicellulose fraction remains intact, hemicellulases are required. Current cellulases tend to have weak hemicellulase activity and are not adequate for the complete conversion of hemicellulose fraction of lignocellulosics. Development of low cost, commercial hemicellulases that work synergistically with cellulases is one of the goals of the current research activities.

Researchers are now focusing on utilizing and improving cellulases and hemicellulases enzymes for use in the biofuel and bioproduct industries. The search for potential sources of cellulolytic enzymes is continuing in the interest of successful bioconversion of lignocellulosic biomass. Although various microorganisms of bacterial as well as fungal origin have been evaluated for their ability to degrade cellulosic substrates into glucose monomers, relatively few microorganisms have been screened for their cellulase production potential [35]. There are definite reports that xylanase supplementation in combination with pretreatment or cellulases during saccharification enhance the yields of sugars $[36,37]$.

\section{Limitations of enzymatic saccharification}

During bioconversion, polysaccharides undergo hydrolysis by an array of cell wall degrading enzymes. However, a major bottleneck in making these processes efficient is that plant cell walls have evolved to resist microbial and enzymatic deconstruction - a factor collectively known as "biomass recalcitrance". Thus, rate-limiting steps in the bioconversion of lignocelluloses are the crystalline recalcitrance of cellulose and the limited number of cellulases i.e. all cellulolytic strains identified are low in one or more type of glycoside hydrolases $(\mathrm{GH})$ required for efficient cellulose hydrolysis (endo-/exo-glucanases, $\beta$ glucanases). In attempts to improve the feasibility of the bioconversion of lignocellulose to biofuel, enzymes must have high adsorption capabilities, high catalytic efficiencies, high thermal stability and low end-product inhibition [28]. In addition, some microorganisms secrete either endoglucanase or $\beta$-glucosidase (components of cellulase complex). Only those organisms, which produce appropriate levels of endoglucanase, exoglucanase and $\beta$-glucosidase, would effectively be capable of degrading native lignocellulose. Trichoderma and Aspergillus have been the organisms of choice for industrial production of cellulases but they are subjected to tight induction regulation mechanisms. Moreover, there are several limitations in achieving higher saccharification yields using these enzymes because of different types of inhibitions experienced. Therefore, there is motivation and need to develop better cellulase preparations which have characteristics, better suited for use in biorefineries, like high catalytic efficiency on insoluble substrate, increased stability at higher temperature, $\mathrm{pH}$ and higher tolerance to end-product inhibition.

Thus far, enzymatic saccharification remains one of the most costly steps in conversion of cellulosic biomass to ethanol and cellulase preparations dedicated for bioethanol industry are hardly available. It has been estimated that the greatest returns in cost savings will be realized by improving conversions of biomass to sugars, increasing hydrolysis yields, reducing enzyme loadings, eliminating or reducing pretreatment [38]. A broader suite of enzymes is required for hydrolysis of cellulose and hemicelluloses to fermentable sugars [39]. Thus, 
enzymatic hydrolysis can be effectively carried out if a mixture of different cellulolytic and accessory enzymes is used.

\section{Recent developments in understanding enzymatic action and enzyme design}

Enzyme technology is generally considered the most sustainable technology for saccharification. Enzymatic hydrolysis of cellulose consists of three steps: adsorption of cellulase enzymes onto the surface of the cellulose, the biodegradation of cellulose to fermentable sugars, and desorption of cellulase [21]. The polysaccharide chains, being tightly packed, require additional factors that would make the substrate more accessible, as has been suggested since the 1950s [40]. In addition to enzymes that act directly on polysaccharides, lignocellulose degrading microorganisms are also found to secrete several proteins, which modify cellulose and enhance its hydrolysis by cellulase. These include the non-enzymatic proteins such as 'expansins' and their fungal and bacterial homologs, the 'swollenins' expressed by $T$. reesei with sequence homology to plant expansins and the similar 'loosenins' produced by Bjerkandera adusta. These interact with cellulosic substrates resulting in expansion, slippage, or lengthening of the components, thereby facilitating the access of glycosyl hydrolases $[17,27]$. Recently, cellulose induced proteins (CIP1 and CIP2) have been found in a transcriptional analysis of $T$. reesei, with some synergistic activity with both GH61 and swollenin and are thought to play a role in the cleavage of hemicellulose-lignin crosslinks [17,41]. Table 1 represents the various hydrolytic enzymes and proteins produced by fungi and bacteria, which help to facilitate the lignocellulose bioconversion process.

Anaerobic biomass degrading microbes breakdown biomass with the use of cell-surface linked discrete multienzyme complexes, called cellulosomes. These are arrays of multiple cellulase and hemicellulase proteins, assembled by specific interactions between 'dockerin' domains on the enzyme and 'cohesins' bound to structural scaffoldins on microbial surface [16,17]. Designing of optimized cellulosomes by synthesizing hybrid scaffoldin molecules that contain cohesins with different binding specificity from different organisms is another recent approach to develop more active cellulose degrading enzymes [20]. Synergies between purified cellulases and xylanases from the thermophilic bacterium, Thermobifida fusca displayed on designer cellulosomes were found to possess higher activity on wheat straw than the corresponding free enzymes [42].

In addition to the catalytic core, many of the enzymes also possess non-catalytic domains including carbohydrate binding modules (CBM) and dockerins which, respectively, anchor the enzyme to targeted substrate or onto scaffoldin to assemble a cellulosome and disrupt the crystalline cellulose microfibrils [17]. Recently, new type of bacterial proteins currently classified as CBM33 (family $33 \mathrm{CBM}$ ) in the Carbohydrate Active Enzymes (CAZy) database and fungal proteins classified as GH61 (family 61glycoside hydrolases) that catalyze oxidative cleavage of polysaccharides have been discovered [17,40]. These copper dependent monooxygenases act on the surfaces of insoluble substrates where they introduce chain breaks in the polysaccharide chains thereby increasing substrate accessibility and potentiating hydrolytic enzymes [40].

\section{Strategies for cellulase improvement}

Cellulases are currently the third largest industrial enzyme worldwide, because of their use in cotton processing, paper recycling, as detergent enzymes, in juice extraction, and as animal feed additives. However, cellulases will become the largest volume of industrial enzyme, if ethanol, butanol, or some other fermentation product of sugars, produced from biomass by enzymes, becomes a major transportation fuel. For this application reconstruction of cellulase cocktails with higher activity on insoluble substrates with high hydrolysis rate and yields is required. Commercial cellulase preparations will need to be tailored to fit both feedstock source and feedstock pretreatment. The various routes to cellulase improvement have been presented in the Figure 1. These include bioprospecting to uncover organisms potentially useful as sources of superior key enzymes, mining plant pathogens for lignocellulosic cell wall degrading enzymes and enzyme engineering to improve the natural diversity of enzymes. Enzyme mixtures of the future comprising accessory enzymes that act on the less abundant linkages found in plant cell walls need to be customized for essential lignocellulolytic activities and their optimum ratios [27]. Enhancement of T. reesei cellulases with crude enzyme preparations from other fungi has been documented and may lead to the identification of novel accessory enzymes for biomass hydrolysis [43]. Accessory enzymes that facilitate more complete utilization of plant biomass could be used to develop less energetically and chemically intensive processing and allow for greater fermentable sugar recovery [43].

\section{Enzyme engineering}

The natural diversity of enzymes could provide a large reservoir that can be further improved by engineering enzymes and strains for increased performance [43]. A number of designer enzymes called glycosynthases, including cellulases and hemicellulases, have been engineered by replacing nucleophilic residues resulting in higher yields of different oligosaccharides [16]. In protein engineering, the three-dimensional structure of an enzyme 
Table 1 Novel hydrolytic enzymes and proteins involved in polysaccharide modification and hydrolysis

Fungi 1 Novel hydrolytic enzymes and proteins involved in polysaccharide modification and hydrolysi

\section{Functio}

Cellulases
Aspergillus, Trichoderma, Anaeromyces, Bacillus, Pseudomonas, Ruminococcus, Fibrobacter, $\quad$ Endo -1,4 $\beta$-D-glucanglucanohydrolase

Pestalotiopsis, Phanerochaete, Fusarium, Clostrdium, Halomonas, Streptomyces, Cellulomonas, $\quad$ (E. C. 3. 2. 1.4)

Orpinomyces, Piromyces

Trichoderma, Penicillium, Aspergillus,

Chaetomium, Fusarium, Pestalotiopsis,

Orpinomyces, Piromyces, Rhizopus

Mycobacterium

Bacillus, Pseudomonas, Clostridium, Paenibacillus, Exoglucanase or 1,4- $\beta$-D-glucan Thermobifida, Cellulomonas, Mycobacterium, cellobiohydrolase (E.C.3.2.1.91) Ralstonia

Aspergillus, Monilia, Phanerochaete Sclerotium, Saccharomyces,

Clostridium, Cellulomonas, Aerobacter, Leuconostoc

$\beta$ - glucosidases or $\beta$-D-glucoside gluco-hydrolase (E.C.3.2.1.21)

\section{Clostridium, Cellvibrio}

Cellodextrin phosphorylase or $(1 \rightarrow 4)-\beta$-D-glucan:phosphate

a-D-glucosyltransferase (E.C. 2.4.1.49)

Fomes annosus

Cellulomonas, Clostridium, Ruminococcus, Thermotoga, Cellvibrio

Cellobiose phosphorylase or cellobiose: phosphate alpha-D-glucosyltransferase (E.C. 2.4.1.20)

Hemicellulases

Aspergillus, Trichoderma, Thermomyces, Fusarium, Anaeromyces, Neocallimastix

Aspergillus, Fusarium, Talaromyces, Trichoderma

Aspergillus, Trichoderma

Aspergillus, Penicillium, Fusarium Trichoderma

Penicillium, Aspergillus, Trichoderma Phanerochaete, Chrysosporium

Fusarium, Beauveria, Penicillium, Trichoderma, Neurospora, Aspergillus

Aspergillus, Trichoderma, Thermoascus

Novel proteins

Trichoderma, Aspergillus, Neosartorya

Humicola, Fusarium, Penicillium,

Neurospora, Gliocladium, Candida,

Pichia, Rhodotorula, Sporobolomyces
Bacillus, Thermoanaerobacterium, Ruminococcus, Geobacillus, Thermopolyspora, Cellulomonas, Streptomyces

Bacillus, Thermoanaerobacterium, Geobacillus,

Cellulomonas, Bacillus, Clostridium, Rhodothermus

Bifidobacterium, Thermobacillus, Bacillus,

Clostridium, Streptomyces

Bacillus, Clostridium, Streptomyces, Fibrobacter,

Pseudomonas, Thermoanaerobacterium

Thermotoga, Bifidobacterium, Streptococcus, Bacillus, Cellulomonas, Clostridium

Thermotoga, Cellvibrio, Bacteroides, Bacillus

Bacillus, Cellulomonas, Clostridium, Myceliophthora
Thermomonospora, Streptomyces, Fibrobacter
Endo-1,4-beta-D-xylanase or 1,4-beta-xylan xylanohydrolase (EC 3.2.1.8)

Xylan $\beta$-1.4-xylosidase (EC 3.2.1.37)

Mannan endo-1,4-beta-mannosidase (EC 3.2.1.78)

Alpha-L-arabinofuranosidase (EC 3.2.1.55)

Acetyl (xylan) esterase (EC 3.1.1.72)

Alpha-L-fucoside fucohydrolase or alpha-L-fucosidase (EC 3.2.1.51)

Alpha-D-glucosiduronate glucuronohydrolase Hydrolysis of O-glycosyl bond to release 4-O-methylglucuronic or a-glucuronidase (EC 3.2.1.139) release xylose residues from the non-reducing termini

Random hydrolysis of ( $1 \rightarrow 4$ )-beta-D-mannosidic linkages

in mannans, galactomannans and glucomannans

Hydrolysis of terminal non-reducing alpha-L-arabinofuranoside residues in alpha-L-arabinosides

Hydrolysis of ester linkages of the acetyl groups in position 2 and/or 3 of the xylose moieties of natural acetylated xylan

Hydrolysis of O-glycosyl bond in xyloglucan to release -fucose residues acid from xylan
Hydrolysis of the internal glycosidic linkages in a random fashion generating oligosaccharides of varying lengths

Hydrolysis of beta-D-glucosidic linkages by releasing mainly cellobiose either from the reducing or non-reducing ends of the chains

Hydrolysis of terminal, non-reducing $\beta$-D-glucosyl residues with release of $\beta$-D-glucose

Catalysis of the reversible phosphorolytic cleavage of cellodextrins ranging from cellotriose to cellohexoses

Catalysis of the reversible phosphorolytic cleavage of cellobiose

Endohydrolysis of $(1 \rightarrow 4)$-beta-D-xylosidic linkages in xylans to

Hydrolysis of ( $\rightarrow$ 4)-beta-D-xylans, to remove successive D-xylose

Homologous to plant expansins which rapidly induce extension of plant cell walls by weakening the noncovalent interactions; Contain an N-terminal carbohydrate-binding module family 1 domain (CBD) with cellulose-binding function and a C-termina expansin-like domain. 
Table 1 Novel hydrolytic enzymes and proteins involved in polysaccharide modification and hydrolysis (Continued)

Bjerkandera adusta

Loosenins

A novel expansin-type protein with part of the sequence similar to the DPBB (double psi beta barrel) domain present in plant

expansins, and fungal $\beta$-1,4-endoglucanase family $45 ;$; Bind

tightly to polysaccharides and show loosening activity which permits sugar release

Contain a carbohydrate-binding module (CBM); Hydrolysis

of the ester linkage between 4-O-methyl-D-glucuronic acid of glucuronoxylan and lignin alcohols 


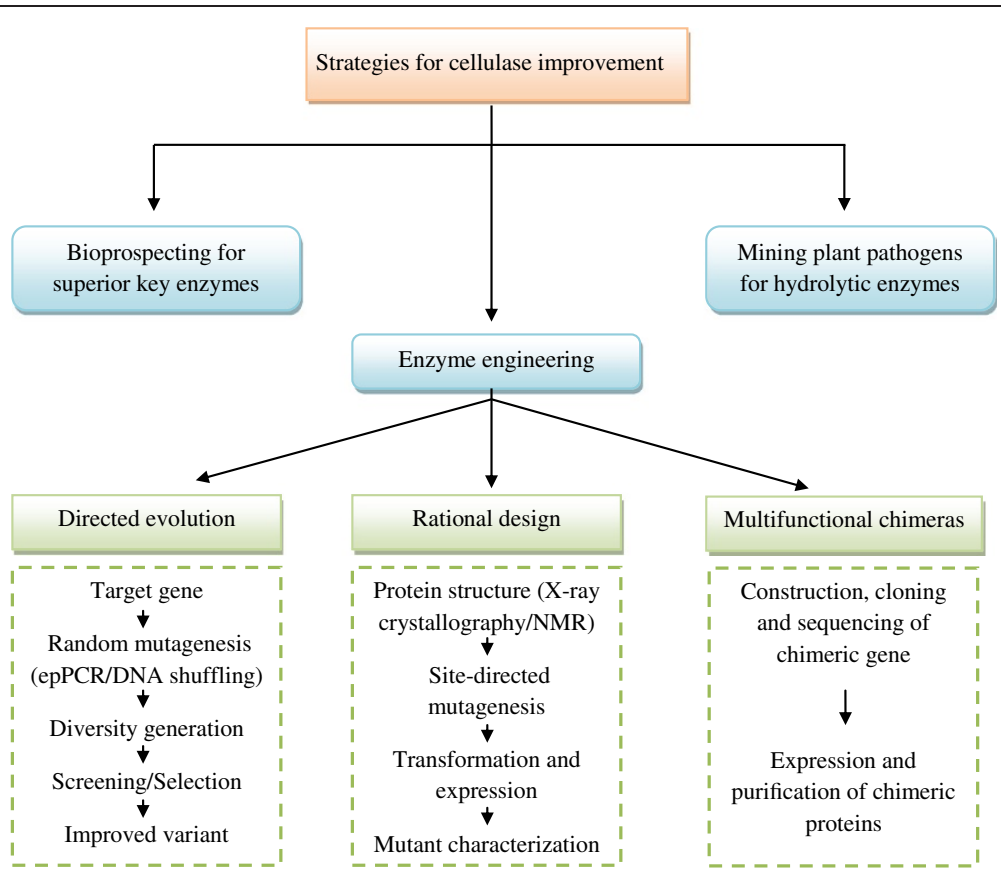

Figure 1 Routes to advancement in cellulase enzyme technology.

guides the identification and modification of amino acid residues, through rational design and directed evolution, which affect some property such as specific activity or thermal stability $[27,44]$.

\section{Rational design}

The process of rational design was introduced after the development of recombinant DNA methods and sitedirected mutagenesis and is still widely used. The approach involves the choice of a suitable enzyme, crystallographic studies to identify the amino acid sites to be changed and characterization of the mutants [44]. Rational design demands a very deep understanding of the catalytic mechanism and additional information on protein structure and functionality. Computational techniques are required to visualize the protein structure and its active site. Amino acid residues can be identified that are important for the docking of the substrate molecule to the active site or for the overall protein stability and sitedirected mutagenesis at these sites is a straightforward way to manipulate enzyme performance [45]. Engineering of enzymes for better thermostability is an area of great interest as it broadens their industrial applications. Structure-based rational design to improve thermostability and specific activity of truncated Fibrobacter succinogenes 1,3-1,4- $\beta$-D-glucanase, which is used as a feed additive, was carried out by Huang et al. [46]. Out of the eleven mutants constructed, the crude protein of V18Y mutant showed a $2^{\circ} \mathrm{C}$ increment of Tm and W203Y showed $\sim 30 \%$ increment of the specific activity. The double mutant V18Y/W203Y showed the same increments of Tm and specific activity as the single mutants did [46]. Recently, Novozymes have developed a versatile enzyme cocktail with increased catalytic activity and thermostability by introduction into a $T$. reesei cellulase mixture, cellobiohydrolase II and beta-glucosidase which have been improved by using consensus sequence analysis and structural modeling [47].

\section{Directed evolution}

Directed evolution or irrational design, contrary to rational design, is an approach to non informational protein engineering which utilizes the power of natural selection to evolve proteins and select for those with desired traits. It requires the use of DNA techniques such as errorprone PCR (epPCR) and DNA shuffling to randomly generate a large library of gene variants. Improved variants are identified in a screen (or selection) that accurately reflects the properties of interest [28]. This approach has become popular to generate tailor-made enzymes. Directed evolution of a thermophilic endoglucanase (Cel5A) from Thermoanaerobacter tengcongensis MB4, displaying an optimal temperature range between 75 and $80^{\circ} \mathrm{C}$, with three rounds of error-prone PCR and screening of 4700 mutants, led to identification of five variants of Cel5A with improved activities [48]. The best variants 3 F6 and C3-13 displayed $135 \pm 6 \%$ and $193 \pm 8 \%$ of the wild type specific activity for the substrate, carboxymethyl cellulose (CMC) [48]. Cellulase improvement strategies based on directed evolution using screening on soluble substrates 
have been only moderately successful [44]. Heterogeneity of insoluble cellulose, unclear dynamic interactions between insoluble substrate and cellulase components, and the complex relationship among cellulase components limit strategies depending on activity screening approaches [44]. Use of insoluble cellulosic substrates could be a powerful selection tool for enriching beneficial cellulase mutants from the large library displayed on the cell surface [44]. Directed evolution of cellulases with improved activity on crystalline cellulose involves the random exchange of either some or even all of the amino acids in a protein and screening of all the arising mutants [49]. By coupling the generation of large variant libraries of genes with the high-throughput screening techniques that select for specific properties of an enzyme, biocatalysts can be optimized for specific applications [50-52].

\section{Multifunctional cellulase chimeras}

Microbial cellulase systems exist in nature in form of free enzymes, cellulosomes or as a newly emerged paradigm, the multifunctional enzymes. The presence of more than one catalytic site and CBM indicate the enforced proximity of multifunctional enzymes that account for an enhanced concerted action on cellulosic substrates [53]. The four different types of multifunctional enzymes that have been described till date include cellulase-cellulase, hemicellulase-hemicellulase, hemicellulase-cellulase and hemicellulase-carbohydrate esterase systems [54]. Using synthetic biology approaches, Moraïs et al. [53] converted two different cellulases from the free enzymatic system of Thermobifida fusca (a family 5 endoglucanase and a family 48 exoglucanase) into bifunctional enzymes, in a single polypeptide chain, with different modular architectures. The combined synergistic action of the two selected cellulases, Cel5A and Cel4bA, was found to mimic the natural multifunctional cellulase-cellulase system [53]. Engineering multifunctional enzymes need continued research efforts and cooperative action of the different enzymatic paradigms to enhance the overall efficiency of plant cell wall degradation.

\section{Bioprospecting}

Many of the cellular traits and biosynthetic characteristics that are sought after in an ideal biofuel-producing microorganism; abilities to degrade lignocellulosic materials, resistance for inhibition by substrates and products can be found in isolated native organisms which may biosynthesize specific biofuels with high yield. The innate power of natural organisms should not be underestimated [55]. Bioprospecting activities can tap two vast sources of microbes: the existing culture collections and a bioprospecting survey of extreme habitats. Bioprospecting for superior key enzymes can be more or less random, or can be guided by evolutionary or ecological principles [27]. It can take the form of isolating microbes that grow better on biomass substrates, mining databases of sequenced genomes, cloning variants of known enzyme genes by polymerase chain reaction (PCR), or finding new genes by metagenomics [27]. Microbial degradation of lignocellulose involves synergistic catalytic activities on a variety of soluble and insoluble substrates. Natural degradation of lignocellulosic biomass by consortium of microorganisms from gut of termites, leaf litter or forest floor involve unique metabolic pathways, cellular tolerances to toxic chemicals and interesting array of enzymes [55]. Many bacterial and fungal plant pathogens are known to produce arsenal of plant cell wall degrading enzymes which can be more potent. Therefore, enzyme prospecting research continues to identify opportunities to enhance enzyme preparations from Trichoderma by supplementing with enzymes from other organisms [43]. One way to optimize conversion is to develop enzyme cocktails to augment the large quantities of commercial enzymes currently used. Recent studies have shown enhanced hydrolysis by supplementing cellulases with accessory enzymes [56].

Several species of actinomycetes are reported to produce cellulases which are more thermostable. Thermomonospora fusca produces a family of cellulases including cellobiohydrolase [57]. Streptomyces sp. has been reported to produce cellulase and also beta glucosidase [58]. Thermostable cellulases produced by Streptomyces transformant T3-1 has been used for various applications in food industry and cellulose conversion [59]. Over the years, cellulase producing, culturable bacteria have been isolated from variety of habitats including composting heaps, decaying plant material, feaces of ruminants, soil and extreme environments. Amongst the novel cellulase producing bacteria are strains of Paenibacillus campinasensis, Bacillus subtilis and Brevibacillus etc. [28]. These are reported to have properties valuable for bioconversion of lignocellulosics. Rational bioprospecting may uncover organisms potentially useful for exploitation in biorefineries.

\section{Mining plant pathogens for cellulolytic and xylanolytic enzymes}

Currently available commercial cellulases and xylanases have been sourced mostly from saprophytic organisms. It is well established that plant pathogens produce array of diverse extracellular hydrolytic and cell wall degrading enzymes which serve as important key virulence factors and help plant pathogens in invading the plant tissues and play an important role in pathogenesis. Recently, King et al., [43] screened and identified 348 unique isolates representing 156 species of plant pathogenic fungi with hydrolytic profile more active than Trichoderma. There is genomic evidence of lignocellulosic cell wall 
degrading enzymes in plant pathogens and full genome sequencing of a number of plant pathogens has revealed often large complex and redundant enzyme systems for degradation of cell walls.

Recent surveys have revealed that plant pathogenic fungi are highly competent producers of lignocellulolytic enzymes and their enzyme activity patterns reflect host specificity. Plant pathogens have gained competitive edge over saprobes by earlier access to plant tissues and long phases of survival and reproduction than a saprobe on plant residues [56]. Thus, hydrolytic enzymes from plant pathogens promise to be more potent. Also, following infection, plants produce proteins as counter defence to inhibit cell wall degrading enzymes (CWDEs) and this interaction drives plant pathogens to evolve more potent unique hydrolytic enzymes [60]. A number of plant pathogenic fungi (Fusarium oxysporum, Phoma betae, Collectotrichium gloeosporioides etc.) have been reported to elaborate high levels of cellulases [61]. The capability of the plant pathogenic fungus Myrothecium verrucari to produce extracellular enzymes in submerged culture has been reported [62].

The pathogenicity of a large number of gram negative bacteria (Xanthomonas, Erwinia and Pseudomonas) relies on their ability to secrete extracellular depolymerising enzymes, such as cellulases, xylanases, proteases and pectinases [63]. Extracellular enzymes directly or indirectly affect the bacterial population and symptoms in the host, and even determine whether or not the infection will be successful. Several researchers have studied the structure/secretion relationship of cellulase in Xanthomonas and Erwinia because of role of this high potency enzyme in pathogenicity/infection [64-66]. Although role of depolymerising enzymes in necrosis and pathogenicity is well documented, the studies on commercial production of cellulases from other plant pathogens including Xanthomonas are almost lacking. Thus, phytopathogens represent sources of promising enzymatic diversity to complement and improve existing cellulase cocktails from Trichoderma.

Plant pathogenic organisms expressing a diverse array of cell wall degrading enzymes (CWDEs), therefore, have greater capabilities of attacking and thriving on plant lignocellulosic biomass and may possess unique set of enzymes or individual cocktails which may complement commercial cellulases for faster and more complete saccharification of biomass carbohydrates. The enzymes elaborated by the plant pathogenic organisms may be more suitable for biochemical conversion of biomass in biorefineries as their host species include potential lignocellulosic feedstocks for biofuel production. Plant pathogens are competent producers of lignocellulolytic enzymes and serve as diverse sources of accessory enzymes for more efficient conversion of lignocellulose into fermentable sugars. Thus, to achieve full potential of biorefineries, there is a pressing need to discover novel and unexploited microbes and their enzyme arsenals. A comprehensive study of cellulases expressed by plant pathogenic bacteria may yield promising enzyme candidates for application in bioethanol industry.

\section{Conclusion}

Given the current robust forces driving sustainable bioproducts production, biomass-based routes are expected to make a significant impact on the production of bulk chemicals in the next decade, and a huge impact in near future. Therefore, technology for conversion of biomass polysaccharides to fermentable sugars has to be optimized and made cost effective. Enzyme cocktails for wide range of biomass feedstocks have to be made available at reduced costs. Having a diverse library of cellulases and other complementary enzymes will enable tailoring such cocktails. Tailoring of cellulase mixtures for improvements in overall performance depends strongly on residual lignocellulosic properties after pretreatment. What has been lacking, however, is a systematic evaluation of the scope of CWDEs in plant pathogens and what particular enzymes might potentially contribute to optimized lignocellulose digestion. Rapid screening of hydrolase and transferase functions will be required to screen for activity (e.g. endo-, exo-, betaglucosidase). With the advent of liquid handling automation, miniaturization of enzyme assays, and high throughput screening methodologies, large enzyme libraries from diverse organisms can be evaluated for their ability to produce CWDEs [56]. To implement protein engineering for improvement of enzyme performance on biomass robust high throughput methods are being devised. Despite extensive research on cellulases, there are major gaps in our understanding of the actual mechanism involved in the hydrolysis of crystalline cellulose, mediated by the synergistic action of various constituents of the cellulase enzyme complex including the accessory enzymes.

\section{Competing interests}

The authors declare that they have no competing interests.

\section{Authors' contributions}

SM and DA wrote most of the manuscript. JC contributed to parts of the manuscript. AA and LN conceptualized and critically reviewed the manuscript. All authors read and approved the final manuscript.

Received: 10 May 2013 Accepted: 17 July 2013

Published: 9 September 2013

\section{References}

1. FAO: Biofuels and agriculture - a technical overview, The state of food and agriculture 2008: Biofuels: prospects, risks and opportunities. Rome, Italy: FAO corporate document repository. Electronic Publishing Policy and Support Branch, FAO; 2008:10-22.

2. Bringezu S, Schütz H, O’Brien M, Kauppi L, Howarth RW, McNeely J: Towards sustainable production and use of resources: Assessing biofuels. UNEP; 2009. http://www.unep.org/PDF/Assessing_Biofuels.pdf 
3. Sukumaran RK, Surender VJ, Sindhu R, Binod P, Janu KU, Sajna KV, Rajasree KP, Pandey A: Lignocellulosic ethanol in India: Prospects, challenges and feedstock availability. Bioresour Technol 2010, 101:4826-4833.

4. Government of India: Report of the Committee on the Development of Biofuel. New Delhi: Planning Commission; 2003. http://planningcommission.nic.in/ reports/genrep/cmtt_bio.pdf (accessed on 20/09/2012).

5. Sánchez OJ, Cardona CA: Trends in biological production of fuel ethanol from different feedstocks. Bioresour Technol 2008, 99:5270-5295.

6. Claassen PAM, van Lier JB, Contreras LAM, van Niel EWJ, Sijtsma L, Stams AJM, de Vries SS, Weusthuis RA: Utilisation of biomass for the supply of energy carriers. Appl Microbiol Biotechnol 1999, 52:741-755.

7. Farrell AE, Plevin RJ, Turner BT, Jones AD, O'Hare M, Kammen DM: Ethanol can contribute to energy and environmental goals. Science 2006, 113:506-508.

8. Wyman CE: Handbook on Bioethanol: Production and utilization. Wasington: Taylor Francis; 1996.

9. Bon EPS, Ferrara MA: Bioethanol production via enzymatic hydrolysis of cellulosic biomass. http://www.fao.org/biotech/docs/bon.pdf.

10. USDOE: Breaking the biological barriers to cellulosic ethanol: $A$ joint research agenda. In Summary of the Biomass to Biofuels Workshop, held 7-9 December 2005. Rockville, United States; 2006. sponsored by the U.S. Department of Energy.

11. Hahn-Hagerdal B, Galbe M, Gorwa-Grauslund MF, Liden G, Zacchi G Bioethanol from-the fuel of tomorrow from residues of today. Trends Biotechnol 2006, 24:549-556.

12. Saeman JF: Kinetics of wood saccharification. Ind Eng Chem 1945, 37:43-52.

13. Wilke CR, Yang RD, von Stockar U: Preliminary cost analyses for enzymatic hydrolysis of newsprint. Biotechnol Bioeng 1976, 6:155-175.

14. Deka D, Jawed M, Goyal A: Purification and characterization of an alkaline cellulase produced by Bacillus subtilis (AS3). Prep Biochem Biotechnol 2013, 43:256-270.

15. Duff SJB, Murray WD: Bioconversion of forest products industry waste cellulosics to fuel ethanol: A review. Bioresour Technol 1996, 55:1-33.

16. Kumar R, Singh S, Singh OV: Bioconversion of lignocellulosic biomass: Biochemical and molecular perspective. J Ind Microbiol Biotechnol 2008, 35:377-391.

17. Sweeney MD, Xu F: Biomass converting enzymes as industrial biocatalysts for fuels and chemicals: Recent developments. Catalysts 2012, 2:244-263.

18. Mandels M, Sternberg D: Recent advances in cellulase technology. Ferment Technol 1976, 54:267-286.

19. Schulein M: Kinetics of fungal cellulases. Biochem Soc Trans 1998, 26:164-167.

20. Wilson DB: Cellulases and biofuels. Curr Opin Biotechnol 2009, 20:295-299.

21. Sun $Y$, Cheng J: Hydrolysis of lignocellulosic materials for ethanol production. Bioresour Technol 2002, 83:1-11.

22. Martins LF, Kolling D, Camassola M, Dillon AJ, Ramos LP: Comparison of Penicillium echinulatum and Trichoderma reesei cellulases in relation to their activity against various cellulosic substrates. Bioresour Technol 2008 99:1417-1424.

23. Sharma A, Khare SK, Gupta MN: Hydrolysis of rice hull by crosslinked Aspergillus niger cellulase. Bioresour Technol 2001, 78:281-284.

24. Valaskova V, Baldrian P: Degradation of cellulose and hemicelluloses by the brown rot fungus Piptoporus betulinus production of extracellular enzymes and characterization of the major cellulases. Microbiology 2006, 152:3613-3619.

25. Kato S, Haruta S, Cui ZJ, Ishii M, Igarashi Y: Stable coexistence of five bacterial strains as a cellulose-degrading community. Appl Environ Microbiol 2005, 71:7099-7106.

26. Kaur G, Kumar S, Satyanarayana T: Production, characterization and application of a thermostable polygalacturonase of a thermophilic mould Sporotrichum thermophile Apinis. Bioresour Technol 2004, 94:239-243.

27. Banerjee G, Scott-Craig JS, Walton JD: Improving enzymes for biomass conversion: A basic research perspective. Bioenerg Res 2010, 3:82-92.

28. Maki M, Leung KT, Qin W: The prospects of cellulase-producing bacteria for the bioconversion of lignocellulosic biomass. Int J Bio/ Sci 2009, 5(5):500-516.

29. Bisaria VS: Bioprocessing of agro-residues to glucose and chemicals. In Bioconversion of Waste Materials to Industrial Products. Edited by Martin AM. London: Elsevier; 1991:210-213.

30. Taylor LE, Henrissat B, Coutinho PM, Ekborg NA, Hutcheson SW, Weiner RM: Complete cellulase system in the marine bacterium Saccharophagus degradans strain 2-40T. J Bacteriol 2006, 188:3849-3861.

31. Weber S, Stubner S, Conrad R: Bacterial populations colonizing and degrading rice straw in anoxic paddy soil. Appl Environ Microbiol 2001, 67:1318-1327.
32. Das SP, Ravindran R, Ahmed S, Das D, Goyal D, Fontes CMGA, Goyal A: Bioethanol production involving recombinant $C$. thermocellum hydrolytic hemicellulase and fermentative microbes. Appl Biochem Biotechnol 2012, 167:1475-1488.

33. Lynd LR, Weimer PJ, van ZyI WH, Pretorius IS: Microbial Cellulose Utilization: Fundamentals and biotechnology. Microbiol Mol Biol Rev 2002, 66(3):506-577

34. Lee J: Biological conversion of lignocellulosic biomass to ethanol. J Biotechnol 1997, 56:1-24.

35. Zeng G, Yu H, Huang H, Xi X, Wang R, Huang D, Huang Li G: Microbial community succession and lignocellulose degradation during agricultural waste composting. Biodegradation 2007, 18:793-802.

36. Remond C, Aubry N, Cronier D, Noel S, Martel F, Roge B, Rakotoarivonina H, Debeire $\mathrm{P}$, Chabbert B: Combination of ammonia and xylanase pretreatments: Impact on enzymatic xylan and cellulose recovery from wheat straw. Bioresour Technol 2010, 101:6712-6717.

37. Kumar R, Wyman CE: Effects of xylanase supplementation of cellulase on digestion of corn stover solids prepared by leading pretreatment technologies. Bioresour Technol 2009, 100:4203-4213.

38. Lynd LR, Laser MS, Bransby D, Dale BE, Davidson B, Hamilton R, Himmel ME, Keller M, McMillan JD, Sheehan J: How biotech can transform biofuels. Nat Biotechnol 2008, 26:169-172.

39. McMillan JD, Jenning EW, Mohagheghi A, Zuccarello M: Comparative performance of precommercial cellulases hydrolyzing pretreated corn stover. Biotech Biofuels 2011, 4:29.

40. Horn SJ, Vaaje-Kolstad G, Westereng B, Eijsink VGH: Novel enzymes for the degradation of cellulose. Biotechnol Biofuels 2012, 5:45. doi:10.1186/1754-6834-5-45.

41. Scott BR, Hill C, Tomashek J, Liu C: Enzymatic hydrolysis of lignocellulosic feedstocks using accessory enzymes. United States Patent Application 2009/0061484, 5 Mar 2009; 2009.

42. Morais S, Barak Y, Caspi J, Hadar Y, Lamed R, Shoham Y, Wilson DB, Bayer EA: Cellulase-xylanase synergy in designer cellulosomes for enhanced degradation of a complex cellulosic substrate. mBio 2010, 1:e00285-00210.

43. King BC, Waxman KD, Nenni NV, Walker LP, Bergstrom GC, Gibson DM: Arsenal of plant cell wall degrading enzymes reflects host preference among plant pathogenic fungi. Biotechnol Biofuels 2011, 4:4.

44. Zhang P, Himmel ME, Mielenz JR: Outlook for cellulase improvement Screening and selection strategies. Biotechnol Adv 2006, 24(5):452-481.

45. Buthe A: Improving on nature's enzymes: Transforming nature's enzymes into the perfect industry catalysts requires a combination of 'time lapse evolution' and expert protein engineering. In Chemistry and Industry. Ten Alps Publishing, March 7, 2011; 2011. http://www.highbeam.com/doc/1G1-251855551.html.

46. Huang JW, Cheng YS, Ko TP, Lin CY, Lai HL, Chen CC, Ma Y, Zheng Y, Huang CH, Zou P, Liu JR, Guo RT: Rational design to improve thermostability and specific activity of the truncated Fibrobacter succinogenes 1,3-1,4-3-D-glucanase. Appl Microbiol Biotechnol 2012, 94(1):111-121.

47. Wogulis M, Bohan DM, Osborn D, Benyamino R: Rational design of CBH IIs and BGs for improved activity and thermostability. http://sim.confex.com/sim/ 34th/webprogram/Paper21296.html.

48. Liang C, Fioroni M, Rodríguez-Ropero F, Xue Y, Schwaneberg U, Ma Y. Directed evolution of a thermophilic endoglucanase (Cel5A) into highly active Cel5A variants with an expanded temperature profile. J Biotechnol 2011, 154(1):46-53.

49. Kubicek CP: The Plant Biomass, in Fungi and Lignocellulosic Biomass. Oxford, UK: Wiley-Blackwell; 2012. doi:10.1002/9781118414514.ch.

50. Turner NJ: Directed evolution of enzymes for applied biocatalysis. Trends Biotechnol 2003, 21(11):474-478.

51. Song JM, Wei DZ: Production and characterization of cellulases and xylanases of Cellulomicrobium cellulans grown in pretreated and extracted bagasse and mineral nutrient medium M9. Biomass Bioenerg 2010, 34:1930-1934.

52. Lehmann C, Sibilla F, Maugeri Z, Streit WR, de María PD, Martinez Z, Schwaneberg U: Reengineering CelA2 cellulase for hydrolysis in aqueous solutions of deep eutectic solvents and concentrated sea water. Green Chem 2012, 14:2719-2726.

53. Moraïs S, Barak Y, Lamed R, Wilson DB, Xu Q, Himmel ME, Bayer EA: Paradigmatic status of an endo- and exoglucanases and its effect on crystalline cellulose degradation. Biotech Biofuels 2012, 5:78. 
54. Himmel M, Xu Q, Luo Y, Ding S, Lamed R, Bayer E: Microbial enzyme systems for biomass conversion: Emerging paradigms. Biofuels 2010, 1:323-341.

55. Alper H, Stephanopoulous G: Engineering for Biofuel: Exploiting innate microbial capacity or importing biosynthetic potential? Nat Rev Microbiol 2009, 7:715-723.

56. Gibson DM, King BC, Hayes ML, Bergstrom GC: Plant pathogens as a source of diverse enzymes for lignocellulose digestion. Curr Opinion Microbiol 2011, 14:264-270.

57. Sakon J, Irwin D, Wilson DB, Karplus PA: Structure and mechanism of endo/exocellulase E4 from Thermomonospora fusca. Nat Struct Biol 1997 4(10):810-818.

58. Arora A, Nain L, Gupta JK: Solid-state fermentation of wood residues by Streptomyces griseus B1, a soil isolate, and solubilisation of lignins. World J Microbiol Biotechnol 2005, 21:303-308.

59. Jang HD, Chen KS: Production and characterization of thermostable cellulases from Streptomyces transformant T3-1. World J Microbiol Biotechnol 2003, 19:263-268.

60. Juge N, Svensson B: Proteinaceous inhibitors of carbohydrate-active enzymes in cereals: Implication in agriculture, cereal processing and nutrition. J Sci Food Agric 2006, 86:1573-1586.

61. Ortega J: Cell wall degrading enzyme produced by phytopathogenic fungus Colletotrichum gloesporiodes. Texas J Sci 1994, 228:1-6.

62. Moreira FG, dos Reis S, Costa MAF, de Souza CGM: Production of hydrolytic enzymes by the plant pathogenic fungus Myrothecium verrucaria in submerged condition. Braz J Microbiol 2005, 36:7-1.

63. Chapon V, Czjzek M, El Hassouni M, Py B, Juy M, Barras F: Type II protein secretion in Gram-negative pathogenic bacteria: The study of the structure/secretion relationships of the cellulase Cel5 (formerly EGZ) from Erwinia chrysanthemi. J Mol Biol 2001, 310:1055-1066.

64. Barras F, van Gijsegem F, Chatterjee AK: Extracellular enzymes and pathogenesis of soft-rot Erwinia. Annual Rev Phytopathol 1994, 32:201-234.

65. Goodwin PH, Sopher CR, Michaels TE: Multiplication of Xanthomonas campestris pv. phaseoli and intercellular enzyme activities in resistant and susceptible beans. J Phytopathol 1995, 143:11-15.

66. Huang $X$, Zhai J, Luo Y, Rudolph K: Identification of a highly virulent strain of Xanthomonas axonopodis pv. malvacearum. Eur J Plant Pathol 2008, 122:461-469.

doi:10.1186/2043-7129-1-15

Cite this article as: Mohanram et al:: Novel perspectives for evolving enzyme cocktails for lignocellulose hydrolysis in biorefineries.

Sustainable Chemical Processes 2013 1:15.

\section{Publish with ChemistryCentral and every scientist can read your work free of charge \\ "Open access provides opportunities to our colleagues in other parts of the globe, by allowing anyone to view the content free of charge." \\ W. Jeffery Hurst, The Hershey Company. \\ - available free of charge to the entire scientific community \\ - peer reviewed and published immediately upon acceptance \\ - cited in PubMed and archived on PubMed Central \\ - yours - you keep the copyright \\ Submit your manuscript here: \\ http://www.chemistrycentral.com/manuscript/<smiles>c1ccccc1</smiles> 